\title{
Model based on Hybridized Game Theory to Optimize Logistics: Case of Blood Supply Chain
}

\author{
Salma Mouatassim \\ LRI ENSEM \\ Km 7 BP8118 Rte El- \\ Jadida
}

\author{
Mustapha \\ Ahlaqqach \\ LRI ENSEM \\ Km 7 BP8118 Rte El- \\ Jadida
}

\author{
Jamal Benhra \\ LRI ENSEM \\ Km 7 BP8118 Rte El- \\ Jadida
}

\author{
My Ali El Oualidi \\ LRI ENSEM \\ Km 7 BP8118 Rte El- \\ Jadida
}

\begin{abstract}
Several researches have been done to optimize different flows in blood supply chain. However, the use of game theory in this sense is rare. The following work focus on the case of Morocco, consisting of 16 Regional Blood Transfusion Centers (RBTC) centralized around a National Blood Transfusion and Hematology Center (NBTHC). An approach based on hybridized game theory is adopted to form core and strongly stable coalitions and optimize as much as possible the transport cost. Firstly, the optimal cost of each coalition of the 33 possible coalitions; that the Director of NBTHC validated; is computed by using a mixed integer linear Programming model (MILP). Then these costs are introduced as data of two other MILP to define which structure minimizes the total cost allocated to each RTBC while maintaining core stability, in the case of the first MILP, and strong equilibrium in the case of the second. The VRPPDTW is also introduced within each coalition in order to optimize the cost of transport more.
\end{abstract}

\section{General Terms}

Mixed integer linear programming, logistics, game theory.

\section{Keywords}

Optimization, Game theory, Blood supply chain, Collaborative logistics, VRPPDTW

\section{INTRODUCTION}

Blood is the most operated human tissue; it plays a crucial role in the hospital sector and in the care units. Its availability is paramount since human lives are at stake, and it is in this framework that the blood transfusion centers are working. Their main mission is the collection and processing of blood in order to meet the needs of patients. This work is interested in the case of Morocco, where the centers are distributed on the regions. There is 16 Regional Blood Transfusion Centers (RBTC) dealing with the collection, processing and separation of blood in order to obtain the Labile Blood Products (LBP); and one National Blood Transfusion and Hematology Center (NBTHC).

The NBTHC plays the role of the intermediary between the different RBTC. In the case where the level of stock available to the delivery is below the safety stock defined, a procurement request in LBP is transmitted to the NBTHC. And in function of the stocks of other RBTC, NBTHC sends a request for a LBP at the nearest center with a further stock. Then the LBP are delivered by this center to the center in deficit.

Thus, the system is centralized around the national blood transfusion and hematology center. Therefore, a simple malfunction at the level of the NBTHC can impact all RBTC and disrupt their main mission which is the provision of necessary blood to the different patients.

Of this fact, there is a problem of interactive optimization; each RBTC seeks to meet its request in BPL. So the game theory can be exploited in order to create coalitions of RBTC to optimize the cost of transport and to best satisfy the requests for BPL and meet the needs of patients. A resolution of a Vehicle Routing Problem with Pickup and Delivery Time Window (VRPPDTW) within each coalition is also proposed, in order to optimize the cost of transport more.

The second section of this paper outlines the state of the art on game theory applied to supply chain, the Section 3 details the problem that the article is dealing with while Section 4 presents the mathematical models developed in the framework of the proposed approach. The simulation of these models is presented in section 5 and the results in section 6 , and then the VRPPDTW within each coalition is introduced in section 7 to finally conclude.

\section{STATE OF THE ART}

Game theory has proved its usefulness in several sectors, particularly in the case of formation of coalitions. Studies have been made in this direction, showing that the collaboration between the players allows optimizing the logistic operations and consequently optimize the gains. [1] and [2] are among the first researchers to have treated cooperative games. [3] Combines the game theory and operational research. [4] Study the configuration of cooperative game. [5] Show the existence of a single and unique stable coalition of suppliers allowing maximizing the profit in an auction. [6] Apply the cooperative game theory in order to minimize the overall cost and allocate costs on a corporate network. [7] Use the core concept for the tiebreaker in the case of cooperative purchasing.

The work of [8] and [9] dealing with cooperative game theory in different contexts, such as the industry of automobile assembly or even the health sector. There is also research concerning the inventory management ([10], [11], [12] and [13]) or transport ([14] and [15]). Nevertheless, the works combining supply chain of blood and game theory remain rare.

Besides, the collaboration allows optimizing the gains and it can be considered that the formation of a grand coalition containing all agents would generate an optimal cost and benefits. However, as the number of partners coordinating grows the cooperation becomes more problematic and/or costly[16]. It must, therefore, take into account the size of each coalition, because that is an important aspect in the collaborative logistics as it defined by [17]. 


\section{PROBLEMATIC}

Morocco has 16 RBTC; each specialized in collection, treatment and separation of blood in order to meet the need in LBP of its region. However, according to the information communicated by the director of the NBTHC [18], some centers are in deficit (Fig1). And according to the current process, any center in deficit must make a request to the NBTHC and wait to be delivered, i.e. that all supplies must pass by the NBTHC. The slightest malfunction of the latter may have very serious repercussions on the whole supply chain.
Therefore coalitions between the different regional centers can be formed, in order to be able to facilitate the process of supply between the RBTC. The goal is to satisfy the requests at a lower cost.

The set of possible coalitions is presented below. [18] has developed scenarios involving the RBTC in areas, where the journey time between two sites does not exceed 6 Hours, and which have been validated by the Director of the NBTHC in order to optimize the human and material resources and better control the production process and quality control and thus ensure an availability and a good level of service of LBP.

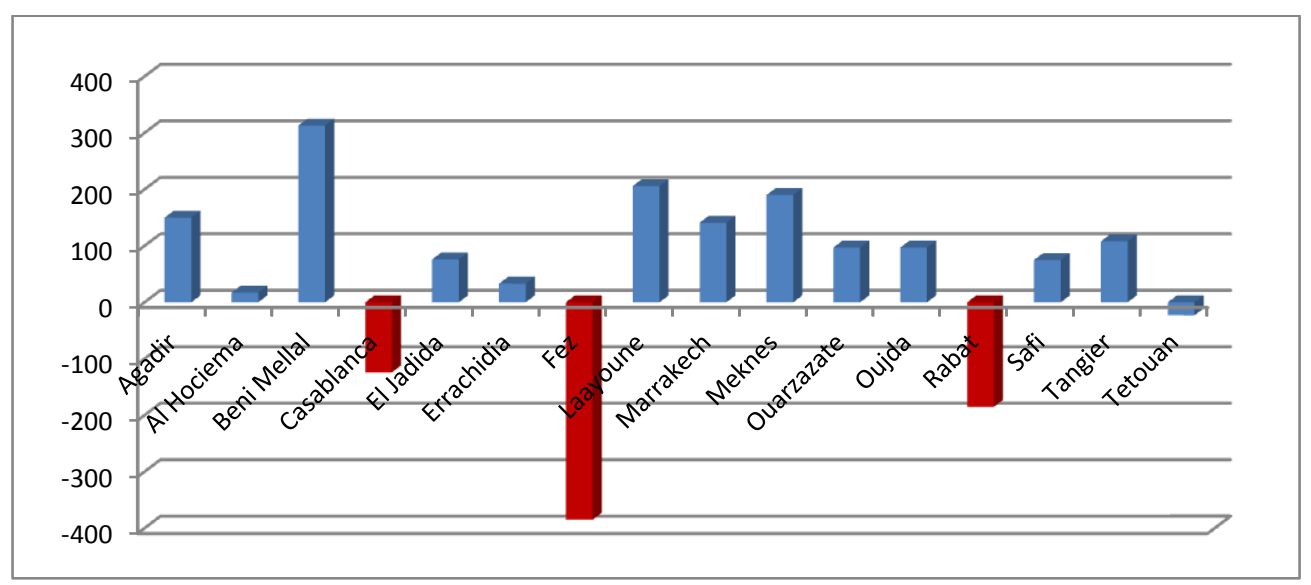

Fig 1: Difference between the real stock and the stock ideal of each RBTC

Table 1. list of coalitions

\begin{tabular}{|c|c|c|c|c|c|c|c|}
\hline 1 & 2 & 3 & 4 & 5 & 6 & 7 & 8 \\
\hline $\begin{array}{l}\text {-Casablanca } \\
\text {-Beni Mellal }\end{array}$ & $\begin{array}{l}\text { - Rabat } \\
\text { - Tangier } \\
\text { - Tetouan } \\
\text { - Méknes }\end{array}$ & $\begin{array}{l}\text { - Marrakech } \\
\text { - Ouarzazate } \\
\text { - Safi }\end{array}$ & $\begin{array}{l}\text { - Fes } \\
\text { - Errachidia }\end{array}$ & $\begin{array}{l}\text { - Oujda } \\
\text { - El Hociema }\end{array}$ & $\begin{array}{l}\text {-Agadir } \\
\text { - Laayoune }\end{array}$ & $\begin{array}{l}\text { - Casablanca } \\
\text { - El Jadida }\end{array}$ & $\begin{array}{l}\text { - Rabat } \\
\text { - Tangier } \\
\text {-Tetouan }\end{array}$ \\
\hline 9 & 10 & 11 & 12 & 13 & 14 & 15 & 16 \\
\hline $\begin{array}{l}\text { - Marrakech } \\
\text { - Safi }\end{array}$ & $\begin{array}{l}\text { - Fes } \\
\text { - Errachidia } \\
\text { - Meknes } \\
\text {-Beni Mellal }\end{array}$ & $\begin{array}{l}\text { - Agadir } \\
\text { - Laayoun } \\
\text { - Ouarzazate }\end{array}$ & $\begin{array}{l}\text { - Casablanca } \\
\text { - Beni Mellal }\end{array}$ & $\begin{array}{l}\text { - Rabat } \\
\text { - Tangier } \\
\text { - Meknes }\end{array}$ & $\begin{array}{l}\text { - Marrakech } \\
\text { - Safi } \\
\text {-El Jadida }\end{array}$ & $\begin{array}{l}\text { - Fes } \\
\text { - Errachidia } \\
\text { - Tetouan }\end{array}$ & $\begin{array}{l}\text { - Marrakech } \\
\text { - Ouarzazate }\end{array}$ \\
\hline 17 & 18 & 19 & 20 & 21 & 22 & 23 & 24 \\
\hline $\begin{array}{l}\text { - Agadir } \\
\text { - Laayoune } \\
\text { - Safi }\end{array}$ & $\begin{array}{l}\text { - Casablanca } \\
\text { - Safi } \\
\text { - El Jadida }\end{array}$ & $\begin{array}{l}\text { - Rabat } \\
\text { - Meknes }\end{array}$ & $\begin{array}{l}\text { - Fes } \\
\text { - Errachidia } \\
\text { - Tangier } \\
\text { - Tetouan } \\
\text { - Beni Mellal }\end{array}$ & $\begin{array}{l}\text { - Rabat } \\
\text { - Meknes } \\
\text { - Tetouan }\end{array}$ & $\begin{array}{l}\text {-Marrakech } \\
\text { - Safi } \\
\text { - Beni Mellal }\end{array}$ & $\begin{array}{l}\text { - Fes } \\
\text { - Errachidia } \\
\text { - Tangier }\end{array}$ & $\begin{array}{l}\text {-Rabat } \\
\text { - Meknes } \\
\text { - Beni Mellal }\end{array}$ \\
\hline 25 & 26 & 27 & 28 & 29 & 30 & 31 & 32 \\
\hline $\begin{array}{l}\text { - Fes } \\
\text { - Errachidia } \\
\text { - Tangier } \\
\text { - Tetouan }\end{array}$ & $\begin{array}{l}\text { - Casablanca } \\
\text { - Safi }\end{array}$ & $\begin{array}{l}\text {-Rabat } \\
\text {-Beni Mellal } \\
\text {-Tangier } \\
\text {-Tetouan }\end{array}$ & $\begin{array}{l}\text { - Marrakech } \\
\text { - El Jadida }\end{array}$ & $\begin{array}{l}\text { - Marrakech } \\
\text { - El Jadida }\end{array}$ & $\begin{array}{l}\text { - Fes } \\
\text { - Errachidia } \\
\text { - Meknes } \\
\text { - Tetouan }\end{array}$ & $\begin{array}{l}\text { - Rabat } \\
\text { - Tangier } \\
\text {-Meknes } \\
\text { - Beni Mellal }\end{array}$ & $\begin{array}{l}\text { - Fes } \\
\text { - Errachidia } \\
\text { - Tetouan } \\
\text {-Beni Mellal }\end{array}$ \\
\hline 33 & & & & & & & \\
\hline $\begin{array}{l}\text { - Fes } \\
\text { - Errachidia } \\
\text { - Tangier } \\
\text { - Beni Mellal }\end{array}$ & & & & & & & \\
\hline
\end{tabular}




\section{MATHEMATICAL MODELS}

In order to take into account the costs of non-satisfaction of requests and the costs of losses in the case of non-use of blood, the mathematical model of regulation of stocks proposed by [18] is adapted. The main purpose of this study is to satisfy the applications since human lives depend on and at less cost.

The mathematical model used to calculate the optimal cost of each coalition is presented below.

Sets:

$\mathrm{N}$ : number of the blood transfusion centers

$\mathrm{K}$ : number of coalitions

$\mathrm{N}_{1 \mathrm{k}}$ : number of surplus centers belonging to the coalition $\mathrm{k}$

$\mathrm{N}_{2 \mathrm{k}}$ : number of deficit centers belonging to the coalition $\mathrm{k}$

Data:

$\mathrm{E}_{\mathrm{i}}$ : gap between the real stock and the stock ideal of a surplus center

$D_{j}$ : gap between the real stock and the stock ideal of a deficit center

$I_{i}$ : level of stock ideal of a blood transfusion center I

$\mathrm{R}_{\mathrm{i}}$ : level of real stock of a blood transfusion center I

$\mathrm{D}_{\mathrm{ij}}$ : distance between the center I and the center $\mathbf{J}$

$\mathrm{C}:$ cost of transport per $\mathrm{km}$

$\mathrm{C}_{\mathrm{d}}$ : cost Per lost pocket

$\mathrm{C}_{\mathrm{ns}}$ : unit cost of non-satisfaction

Decision Variables:

$\mathrm{Q}_{\mathrm{ij}}$ : entire quantity which passes from the center I to the center J

$\mathrm{X}_{\mathrm{ij}}=\begin{array}{rr}1 & \text { if } \quad \mathrm{Q}_{\mathrm{ijk}} \neq 0 \\ 0 & \text { else }\end{array}$

Objective function:

$$
\begin{gathered}
\min C_{k}=\sum_{i=1}^{N 1 k} \sum_{j=1}^{N 2 k} c * d_{i j} * x_{i j}+\sum_{i=1}^{N 1} P P_{i} * C_{d} \\
+\sum_{j=1}^{N 2} D^{N} S_{j} * C_{n s}
\end{gathered}
$$

Constraints:

$$
\begin{gathered}
\alpha= \begin{cases}1, & \text { si } \sum_{i=1}^{N 1 k} E_{i} \geq \sum_{j=1}^{N 2 k} D_{j} \\
0, & \text { sinon }\end{cases} \\
\beta= \begin{cases}1, & \text { si } \sum_{i=1}^{N 1 k} E_{i}>\sum_{j=1}^{N 2 k} D_{j} \\
0, & \text { sinon }\end{cases}
\end{gathered}
$$

$$
\begin{array}{cc}
E i-M * \beta \leq \sum_{j=1}^{N} Q_{i j} \leq E_{i} & \forall i \in\{1 \ldots N 1\} \\
D_{j}-M *(1-\alpha) \leq \sum_{i=1}^{N 1 k} Q_{i j} \leq D_{j} \quad & \forall j \in\{1 \ldots N 2\} \\
P_{i}=E_{i}-\sum_{j=1}^{N} Q_{i j} & \forall i \in\{1 \ldots N 1\} \\
D N S_{j}=D_{j}-\sum_{i=1}^{N 1} Q_{i j} & \forall j \in\{1 \ldots N 2\} \\
Q_{i j} \leq x_{i j} \leq Q_{i j} & \forall i \in\{1 . . N 1\} \forall j \in\{1 . . N 2\} \\
M &
\end{array}
$$

The objective function allows minimizing the cost of each coalition, by taking into account the cost of transportation, the cost generated by the blood bags non-used as well as the cost of non-satisfaction of requests. The constraints (2) and (3) shall ensure that the quantity transferred from a surplus center $i$ does not exceed its surplus and that each center in deficit $j$ does not receive more than its deficit, taking into consideration the different possible cases $\left(\sum_{\mathrm{i}=1}^{\mathrm{N} 1 \mathrm{k}} \mathrm{Ei} \geq\right.$ $\left.\sum_{\mathrm{j}=1}^{\mathrm{N} 2 \mathrm{k}} \mathrm{Dj} ; \sum_{\mathrm{i}=1}^{\mathrm{N} 1 \mathrm{k}} \mathrm{Ei}<\sum_{\mathrm{j}=1}^{\mathrm{N} 2 \mathrm{k}} \mathrm{Dj}\right)$. The constraint (4) calculates the lost bags or non-used and the constraint (5) calculates the non-satisfied requests, while the constraint (6) binds the two variables of decision $\mathrm{x}_{\mathrm{ij}}$ and $\mathrm{Q}_{\mathrm{ij}}$. The last constraint (7) defines the binary nature of $x_{i j}$ and the positivity of $\mathrm{Q}_{\mathrm{ij}}, \mathrm{PP}_{\mathrm{i}}, \mathrm{DNS}_{\mathrm{j}}$.

Game theory is used in order to create coalitions of RBTC collaborating between them at the level of the inventory of labile blood products. [19] are studying several references in the management of collaborative warehouses. However, the use of game theory in this direction remains uncommon [20] especially with regard to the stocks of blood and its supply chain in general. This study refers to the work of [16], based on the core concept and the stability as presented in [21], consider a game consisting of a set of $\mathrm{N}$ players, note $\mathrm{C}_{\mathrm{Z}}$ the cost generated by the coalition $\mathrm{Z}$ with $\mathrm{Z} \subset \mathrm{Nu}=$ $\left(u_{1}, u_{2}, \ldots, u_{n}\right)$, the vector of the costs assigned to each player, is said to belong to the game core if it meets the following constraints:

$$
\begin{gathered}
\sum_{j \in Z} u_{j} \leq C_{z} \quad \forall Z \subset N \\
\sum_{j \in N} u_{j}=C_{N}
\end{gathered}
$$

The constraint (8) corresponds to the rationality of the players, which guarantees that no subset of $\mathrm{Z}$ will receive a cost cheaper than the cost $U$ if it forms a coalition separately from the other. And the constraint (9) ensures the effectiveness, thus the sum of the costs assigned to each player is equal to the optimal cost of the grand coalition $\mathrm{C}_{\mathrm{N}}$. 
The proposed mathematical model is the following:

Data:

$\mathrm{C}_{\mathrm{k}}$ : the total cost of the coalition $\mathrm{k}$

$\alpha_{\mathrm{j}, \mathrm{k}}= \begin{cases}1 & \text { if the gamer i belongs to the coalition } \mathrm{k} \\ 0 & \text { else }\end{cases}$

$\beta_{\mathrm{k}^{\prime}, \mathrm{k}}= \begin{cases}1 & \text { if the coalition } \mathrm{k}^{\prime} \text { is a sub }- \text { coalition of } \mathrm{k} \\ 0 & \text { else }\end{cases}$

Decision Variables:

$\mathrm{x}_{\mathrm{k}}=\left\{\begin{array}{cc}1 & \text { if the coalition } \mathrm{k} \text { is formed } \\ 0 & \text { else }\end{array}\right.$

$\mathrm{u}_{\mathrm{i}, \mathrm{k}}$ : cost allocated to the player $\mathrm{i}$ in the coalition $\mathrm{k}$

Objective function:

$$
\min \sum_{\mathrm{j} \in \mathrm{N}} \sum_{\mathrm{k} \in \mathrm{K}} \mathrm{u}_{\mathrm{j}, \mathrm{k}}
$$

Constraints:

$$
\begin{array}{lr}
\sum_{\mathrm{j} \in \mathrm{N}} \alpha_{\mathrm{j}, \mathrm{k}^{\prime}} * \mathrm{u}_{\mathrm{j}, \mathrm{k}} \leq \mathrm{C}_{\mathrm{k}^{\prime}} * \mathrm{x}_{\mathrm{k}} & \forall \mathrm{k}^{\prime}, \mathrm{k} \in \mathrm{K}: \beta \mathrm{k}^{\prime}, \mathrm{k}=1 \\
\sum_{\mathrm{j} \in \mathrm{N}} \alpha_{\mathrm{j}, \mathrm{k}} * \mathrm{u}_{\mathrm{j}, \mathrm{k}}=\mathrm{C}_{\mathrm{k}} * \mathrm{x}_{\mathrm{k}} & \forall \mathrm{k} \in \mathrm{K} \\
\sum_{\mathrm{k} \in \mathrm{K}} \alpha_{\mathrm{j}, \mathrm{k}}=1 & \forall \mathrm{j} \in \mathrm{N}
\end{array}
$$

$$
\mathrm{x}_{\mathrm{k}} \in\{0,1\}, \quad \mathrm{u}_{\mathrm{j}, \mathrm{k}} \geq 0 \quad \forall \mathrm{j} \in \mathrm{N}, \mathrm{k} \in \mathrm{K}
$$

The objective function (10) minimizes the total cost assigned to each player. The constraint (11) corresponds to the rationality of the players, the constraint (12) ensures that the sum of the costs assigned to each player of a coalition $\mathrm{k}$ is equal to the optimal cost of this coalition $\mathrm{C}_{\mathrm{k}}$. The constraint (13) ensures that each player is part of a single coalition. And finally the constraint (14) defines the binary nature of $x_{k}$ and the positivity of $\mathrm{u}_{\mathrm{j}, \mathrm{k}}$.

The structure of coalition which results from this model ensures that the players of a same coalition have no interest to deviate and form a coalition apart. However, it does not ensure that the players who belong to different coalitions have no interest to form a coalition separately from the existing ones. Then, the concept of equilibrium in the strong sense is introduced, in order to ensure not only the stability within each coalition formed but also the stability of the entire structure. To do this, an additional constraint is added [16]. The objective function is kept (10) as well as the constraints from (12) to (14) and the constraint (11) is replaced by the following constraint:

$$
\sum_{\mathrm{j} \in \mathrm{N}}\left(\alpha_{\mathrm{j}, \mathrm{k}} * \mathrm{u}_{\mathrm{j}, \mathrm{k}^{\prime}}\right) \leq \mathrm{C}_{\mathrm{k}} \quad \forall \mathrm{k} \in \mathrm{K}
$$

The first MILP generates the optimal costs $c_{k}$ of each coalition of the 33 proposed coalitions, taking into account transportation costs, loss of pockets non-used and requests non-met, and then the second MILP allows defining the coalitions to form depending on core-stability and strong stability in order to minimize the total cost.
The previous two models are implemented in Solver using a Windows machine, a microprocessor core i3 and $4 \mathrm{~GB}$ of RAM.

\section{Results}

In order to focus on the main purpose of this study, it assumed that the cost of non-satisfaction of demand is relatively high, given that human lives depend on these blood bags.

[16] have a proposal which links the results of the two models used to define the structure of stable coalitions within the meaning of the core and in the strong sense. The optimal structure which solved the strong stability model, if it exists, is also the optimal solution of core-stability model. In this case of figure, the results exposed on the table 2 are obtained

\begin{tabular}{|c|c|c|c|}
\hline Coalitions & $\mathrm{C}_{\mathrm{k}}$ & Requests non-satisfied & $\mathbf{x}_{\mathrm{k}}$ \\
\hline 1 & 27550 & 0 & 0 \\
\hline 2 & 10065 & 0 & 0 \\
\hline 3 & 31300 & 0 & 0 \\
\hline 4 & 3521820 & 352 & 0 \\
\hline 5 & 11400 & 0 & 1 \\
\hline 6 & 35600 & 0 & 1 \\
\hline 7 & 500495 & 50 & 0 \\
\hline 8 & 1001390 & 100 & 0 \\
\hline 9 & 21600 & 0 & 0 \\
\hline 10 & 16845 & 0 & 0 \\
\hline 11 & 45300 & 0 & 0 \\
\hline 12 & 19950 & 0 & 0 \\
\hline 13 & 11990 & 0 & 0 \\
\hline 14 & 29200 & 0 & 0 \\
\hline 15 & 3751820 & 375 & 0 \\
\hline 16 & 23800 & 0 & 1 \\
\hline 17 & 43100 & 0 & 0 \\
\hline 18 & 4475 & 0 & 1 \\
\hline 19 & 1190 & 0 & 1 \\
\hline 20 & 7935 & 0 & 1 \\
\hline 21 & 181980 & 18 & 0 \\
\hline 22 & 52900 & 0 & 0 \\
\hline 23 & 2443335 & 244 & 0 \\
\hline 24 & 32490 & 0 & 0 \\
\hline 25 & 2673265 & 267 & 0 \\
\hline 26 & 491280 & 49 & 0 \\
\hline 27 & 22975 & 0 & 0 \\
\hline 28 & 21700 & 0 & 0 \\
\hline 29 & 24900 & 0 & 0 \\
\hline 30 & 1852120 & 185 & 0 \\
\hline 31 & 43290 & 0 & 0 \\
\hline 32 & 623265 & 62 & 0 \\
\hline 33 & 9860 & 0 & 0 \\
\hline
\end{tabular}
by compiling the model of core-stability. Then the existence of a combination completing the constraints of strong stability is verified and the results were the same as those on the table 2.

Table 2. Results 
The combination of coalition obtained is therefore the following:

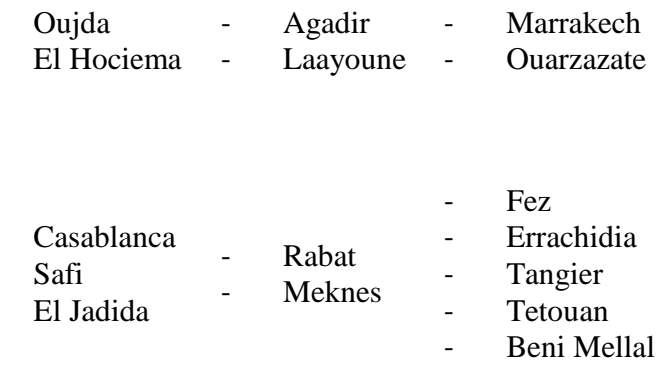

This combination allows us to achieve the objective of this study, which is the satisfaction of demands (the number of requests non-satisfied in this case is 0 ) and the reduction of non-used blood bags while minimizing the cost of transportation and ensuring a strong stability of the structure.

In this case, and given that the main purpose is to meet the needs of patients, a cost of non-satisfaction is considered high which makes the cost of transport negligible. Nevertheless, the proposed model takes into consideration to satisfy all the requests to lower cost. This explains the formation of the coalition (Fez, Errachidia, Tangier, Tetouan, Beni Mellal) despite the large distances between the different cities such as Tangier-Errachidia, the centers in these two cities are surplus. Within this coalition the RBTC of Fez is supplied from the RBTC of Tangier and Beni Mellal while the RBTC of Tetouan is supplied from the RBTC of Tangier.

Motivated by the context of a collaborative blood logistics, a mixed integer linear programming model was formulated to generate the optimal costs of each coalition of 33 coalitions, approved by the Director of the NBTHC. To then be able to introduce them as data of the second MILP aimed to decide what coalitions form and what combination will meet the needs of patients at a lower cost. While guaranteeing stability within each coalition (the core stability) as well as the stability between the different coalitions formed (strong stability).

This approach has allowed us to achieve the desired objective, which is the satisfaction of applications while optimizing the cost of transport. This study has been able to optimize the procurement process and the final result was a set of coalitions self-sufficient and stable even in the strong sense. In the following, a Vehicle Routing Problem with Pickup and Delivery Time Windows is introduced in order to focus on transportation cost.

\section{VRPPDTW}

Now as coalitions were defined, the main objective is to propose a model which ensures optimal transport between blood transfusion centers within each coalition. So, the transporter picks up excess blood bags in superfluous centers and serves deficit centers with their needs. The aforementioned optimal transport in this proposed model means to improve the service of each center in terms of meeting a task demand (pickup or delivery) in a specific time windows at minimum total cost of transport. This model is part of the Vehicle Routing Problem with Pickup and Delivery with Time Windows (VRPPDTW), which is a generalization of the Vehicle Routing Problem with Time Windows (VRPTW)[22]. The Vehicle Routing Problem (VRP) is defined as a class of problems in which the demands of customers are fulfilled with the products originating from depot and transported using a fleet of vehicles in such a way that the total traveling cost of all vehicles is minimized[23].

These issues are considered early as the generalized form of the Traveling Salesman Problem (TSP) formulated by [24]. In the context of this study it is to ensure the vehicle routing while respecting the time windows, that is to say the vehicle is forced to respect the time in which centers will be served. These problems are baptized the Time Window Vehicle Routing Problem (TWVRP). [25] developed an exact algorithm for TWVRP and they tested the algorithm with problems Benchmark Solomon[26]. The work of [27] and [28] are part of the recent work related to TWVRP, they assumed that the deliveries to customers may be outside the time window (soft time windows) but they induced late penalties in the objective function. On the contrary, [29] and [30] have adopted a strict system (Hard time windows) where it is not possible to deliver outside the window of time. This latter system matches the model of this study and a truck has to wait if it arrives at a center before service time, and no deliver or pickup should be done beyond the upper limit of the time window.

The majority of the studies cited above assume that the fleet is homogenous; nevertheless, the reality of companies is that their available fleet is often heterogeneous. This heterogeneity is due to several factors: the diversity of the park to face regulatory and technical constraints (narrow roads, parking places available ...), investment in capacity from one year to another, the merging companies, the purchase of a fleet at a good price....

[31] was among the first to formally define the Heterogeneous Fleet Vehicle Routing Problem (HFVRP). In the context of this paper, the heterogeneity of the fleet will be incorporated, as the study considers a fleet of vehicles characterized by their different capacities and costs.

As mentioned earlier, within each coalition, tours between transfusion centers will be made in order to optimize transportation cost, thus there may be more than one tour in each coalition, and then the field of this problem is a multivehicle VRPPDTW. This field was studied by[32], whose model objective is to minimize the total travel cost. They presented an exact algorithm, which used a column generation scheme with a shortest path sub-problem to solve this model subjected to constraints of time window, capacity, precedence and coupling. Based on the column generation algorithm to compute the lower bounds, [33] proposed a new branch-andcut-and-price algorithm to solve VRPPDTW. In order to take into consideration two different objective functions: the route costs and vehicle fixed costs, [34] presented an exact algorithm for the VRPPDTW based on a set-partitioning formulation improved by additional cuts. In this case, as the fleet is supposed to be heterogeneous, fixed and variable cost in the objective function will be introduced. [35] proposed two different branch-price-and-cut algorithms to solve models and algorithms for the pickup and delivery vehicle routing problem with time windows and multiple stacks. This algorithm, applied in case of the transportation of heavy or dangerous material, gives good results with instances up to 75 according to the authors.

The peculiarity of this routing optimization model of blood bag compared with existing models:

The fleet of vehicles is supposed heterogeneous and its use is limited as required; 
The depot in each routing will be the best departure center which will optimize the objective function. So the model will define for each tour what will be the best departure center. To cope with this issue it is supposed in this model that there is a common depot whose distance to all centers is null, which obviously makes the depot a virtual one, then a constraint which calculates dynamically the distance between the last node visited in a routing and the virtual depot will be introduced. The latter distance is normally the distance between the last center visited and the departure center;

For the sake of simplicity it is assumed that all distances are symmetrical and that the travel time is not time dependent.

\subsection{Mathematical Formulation}

The mathematical formulation aims to minimize the total cost of transport while taking into account the elements that differentiate the proposed model such as: The use of a heterogeneous fleet, the unknown depart of vehicle and use limited vehicles as required. The parameters of model are:

The PDPTWMS can be defined on a directed graph $\mathrm{G}=$ (N,A), where:

$\mathrm{N}=\{0,1, \ldots, \mathrm{n}\}$ is the set of nodes and $\mathrm{A}$ is the set of arcs where $\mathrm{n}$ is the number of transfusion center and 0 is a virtual depot.

The subsets $\mathrm{P}=\{1, \ldots, \mathrm{n}\}$ : the sets of pickup or delivery transfusion centers.

With each request $i$ is associated a pickup node $i \in P$, where a request to pick up is strictly positive and a demand to deliver is null. Beside a delivery node $\mathrm{i} \in \mathrm{P}$, where a demand to deliver is strictly positive and a request to pick up is null.

$\operatorname{Dem}_{\mathrm{i}}:$ a demand to deliver in each node $\mathrm{i} \in \mathrm{P}$,

$\mathrm{Pu}_{\mathrm{i}}:$ a request to pick up in each request $\mathrm{i} \in \mathrm{P}$,

$b_{i}$ : the earliest time at which service at node $i$ can start $i \in N$,

ei: the latest time at which service at node $i$ can start $i \in N$,

$\mathrm{K}$ : set of heterogeneous vehicles,

$\mathrm{Ca}_{\mathrm{k}}$ : carrying capacity of the vehicle $\mathrm{k}, \mathrm{k} \in \mathrm{K}$,

Cfixe $_{\mathrm{k}}$ : fixed cost if vehicle $\mathrm{k}$ is used,

Cvar : transport variable cost

$\mathrm{s}_{\mathrm{i}}$ : service time at node $\mathrm{i}, \mathrm{i} \in \mathrm{N}$

$d_{i j}$ : distance between node $i$ and node $j,(i, j) \in N$

$\mathrm{V}_{\mathrm{k}}$ : average velocity of vehicle $\mathrm{k}, \mathrm{k} \in \mathrm{K}$,

$t_{i j}$ : travel time between node $\mathrm{i}$ and node $\mathrm{j}, \mathrm{t}_{\mathrm{ij}}=\mathrm{V}_{\mathrm{k}} * \mathrm{~d}_{\mathrm{ij}},(\mathrm{i}, \mathrm{j}) \in$ $\mathrm{N}, \mathrm{k} \in \mathrm{K}$,

$c_{i j}$ : traveling time from node $i$ to node $j=s i+t i j,(i, j) \in N$,

$\mathrm{Z}_{1}$ : total cost of routing (Variable cost + fixed cost of used vehicles)

Decision variables:

$\mathrm{x}_{\mathrm{ijk}}$ : a binary variable equal to 1 if $\operatorname{arc}(\mathrm{i}, \mathrm{j})$ is used by vehicle $\mathrm{k}, 0$ otherwise, $\forall(\mathrm{i}, \mathrm{j}) \in \mathrm{N}, \mathrm{k} \in \mathrm{K}$

$\mathrm{y}_{\mathrm{k}}$ : a binary variable equal to 1 if vehicle $\mathrm{k}$ is used, 0 otherwise, $\forall \mathrm{k} \in \mathrm{K}$

$\mathrm{tw}_{\mathrm{i}}$ : a continuous variable which shows waiting time at node $\mathrm{i} ;, \forall \mathrm{i} \in \mathrm{N}$
$\mathrm{T}_{\mathrm{ik}}$ : a continuous variable which shows the departure time of request from node $\mathrm{i}, \forall \mathrm{i} \in \mathrm{N}$

$\mathrm{G}_{\mathrm{ik}}$ : a continuous variable which represents available blood bag in the vehicle $\mathrm{k}$ when arriving to node $\mathrm{i}$

$\mathrm{V}_{\mathrm{ik}}$ : a continuous variable which represents the remaining capacity of vehicle $\mathrm{k}$ when arriving to node $\mathrm{i}$

$\mathrm{Ta}_{\mathrm{k}}$ : a continuous variable which shows the time at which vehicle $\mathrm{k}$ returns to its depot $\mathrm{k} \in \mathrm{K}$

$\mathrm{Td}_{\mathrm{k}}$ : a continuous variable which shows the departure time of a vehicle $\mathrm{k}$ from its depot node $\mathrm{k} \in \mathrm{K}$

$\mathrm{Gd}_{\mathrm{k}}$ : a continuous variable which represents the departure available blood bag in the vehicle $\mathrm{k}$ at depot

$\mathrm{Vd}_{\mathrm{k}}$ : a continuous variable which represents the departure available capacity of vehicle $\mathrm{k}$ at depot

$\mathrm{Ga}_{\mathrm{k}}$ : a continuous variable which represents the available blood bag in the vehicle $\mathrm{k}$ when it returns to its depot $\mathrm{k} \in \mathrm{K}$

$\mathrm{Va}_{\mathrm{k}}$ : a continuous variable which represents the available capacity of vehicle $\mathrm{k}$ when it returns to its depot $\mathrm{k} \in \mathrm{K}$

$D_{i k}$ : the distance between the last center visited and the first departure center

Minimize $Z_{1}$

$$
\begin{aligned}
Z_{1}=\sum_{k=0}^{K} y_{k} * C \text { fixe }_{k} & + \text { Cvar } \\
& *\left(\sum_{i=0}^{n} \sum_{j=0}^{n} \sum_{k=1}^{K} x_{i j k} * C_{i j}\right. \\
& \left.+\sum_{i=0}^{n} \sum_{k=1}^{n} D_{k i}\right)
\end{aligned}
$$

$\sum_{i=0}^{n} \sum_{k=1}^{K} x_{i j k}=1 \quad j \in P$

$\sum_{j=0}^{n} \sum_{k=1}^{K} x_{i j k}=1 \quad i \in P$

$\sum_{i=0}^{n} x_{i p k}=\sum_{j=0}^{n} x_{p j k} \quad p \in P, k \in K$

$\sum_{j=1}^{n} x_{0 j k}=y_{k} \quad k \in K$

$\sum_{i=1}^{n} x_{i 0 k}=y_{k} \quad k \in K$ 
$x_{i i k}=0$

$i \in\{0, \ldots, n\}, k \in K$

$T_{i k}+s_{i}+t_{i j}+t w_{j}-T_{j k} \leq\left(1-x_{i j k}\right) * M$

$i, j \in I, k \in K$

$$
\begin{aligned}
\left(-1+x_{i 0 k}\right) * M \leq & T_{i k}+s_{i}+D_{i k} * V_{k}-T a_{k} \\
& \leq\left(1-x_{i 0 k}\right) * M
\end{aligned}
$$

$i \in P, k \in K$

$\left(-1+x_{0 j k}\right) * M \leq T_{d k}+t_{0 j}-T_{j k}$

$$
\leq\left(1-x_{0 j k}\right) * M
$$

$j \in P, k \in K$

$b_{i} * y_{k} \leq T_{i k} \leq e_{i} * y_{k}$

$i \in P, k \in K$

$b_{0} * y_{k} \leq T a_{k} \leq e_{0} * y_{k}$

$k \in K$

$b_{0} * y_{k} \leq T d_{k} \leq e_{0} * y_{k}$

$k \in K$

$$
\begin{aligned}
\left(-1+x_{0 j k}\right) * M \leq & G_{i k}-G d_{k} \\
& \leq\left(1-x_{0 j k}\right) * M
\end{aligned}
$$$$
j \in P, k \in K
$$

$$
\begin{aligned}
\left(-1+x_{0 j k}\right) * M \leq & V_{i k}-V d_{k} \\
& \leq\left(1-x_{0 j k}\right) * M
\end{aligned}
$$$$
i \in P, k \in K
$$

$$
\left(-1+x_{i 0 k}\right) * M \leq G a_{k}-G_{i k}+D_{e m}-P u_{i}
$$$$
\leq\left(1-x_{i 0 k}\right) * M
$$$$
j \in P, k \in K
$$

$$
\begin{aligned}
\left(-1+x_{i 0 k}\right) * M \leq & V a_{k}-V_{i k}-D e m_{i}+P u_{i} \\
& \leq\left(1-x_{i 0 k}\right) * M
\end{aligned}
$$

$i \in P, k \in K$

$$
\begin{aligned}
\left(-1+x_{i j k}\right) * M \leq & G_{j k}-G_{i k}+D_{e m}-P u_{i} \\
& \leq\left(1-x_{i j k}\right) * M
\end{aligned}
$$

$i, j \in P, k \in K$

$\left(-1+x_{i j k}\right) * M \leq V_{j k}-V_{i k}-D_{e m}+P u_{i}$ $\leq\left(1-x_{i j k}\right) * M$

$i, j \in P, k \in K$

$G_{j k}+c a_{k} * y_{k} \geq\left(-1+x_{i j k}\right) * M \quad i, j \in P, k \in K$

$$
G_{j k}-\operatorname{dem}_{j} \geq\left(-1+x_{i j k}\right) * M \quad i, j \in P, k \in K
$$

$$
V_{j k}-P_{u j} \geq\left(-1+x_{i j k}\right) * M \quad i, j \in P, k \in K
$$

$$
\begin{aligned}
\left(-2+x_{i 0 k}+x_{0 j k}\right) & * M \leq D_{i k}-d_{i j} \\
\leq\left(2-x_{i 0 k}-x_{0 j k}\right) * M & \\
& i, j \in P, k \in K
\end{aligned}
$$

$\mathrm{x}_{\mathrm{ijk}}, \mathrm{y}_{\mathrm{k}} \in\{0,1\} ;$

$$
\begin{aligned}
& t w_{i}, T_{i k}, q_{i k}, T a_{k}, T d_{k}, G_{i k}, V_{i k}, D_{i k} \in \mathbb{R}^{+} \\
& i \in\{0 . . n\}, k \in K
\end{aligned}
$$

The equations (16)-(17) minimize the total travel cost (fixed and variable) of the pickup and delivery vehicles subject to constraints (18) to (41). The equation (18) gives initial value respectively to the capacity and the load of vehicle at depot. Constraints (19)-(20) assure that all pickup and delivery nodes are visited exactly once by the same vehicle. Flow conservation is considered in Constraints (21). Constraints (22)-(23) guarantee that each vehicle leaves its depot at most once and its route starts and ends at the depot. The loop is avoided by the constraint (24). Constraints (25)-(30) compute the time variables and ensure that the time windows are respected, also they avoid sub-tours. Constraints (31)-(36) compute the available blood bag variables and available capacity before each transfusion center according to the arcs used in the solution and constraint (37) ensures that the capacity of each vehicle is respected. Constraint (38) guarantees the availability of blood bag to satisfy the next deliver center and constraint (39) ensures that the available capacity of vehicle $\mathrm{k}$ is enough to serve the next pickup center. Constraint (40) calculates dynamically the distance between the last node visited in a routing and the virtual depot, this distance is normally the distance between the last center visited and the departure center. Finally, constraint (41) defines the variables.

\subsection{Experimentation and Results}

The proposed algorithm is implemented in a Solver. All experiments were conducted on a PC Intel® CORE Duo CPU $2.53 \mathrm{GHz}$ speed and $3 \mathrm{~GB}$ RAM. First, the results of a coalition which contains a big number of transfusion centers are presented in order to validate the proposed model. Second, the model is generalized to all the other coalition.

\subsubsection{Model validation}

The validation process of the coalition which contains a big number of cities, namely: Fez, Errachidia, Tangier, Tetouan and Beni Mellal and a fleet size of 10 is presented in the table below.

Table 3. Transfusion centers parameters in the computational experiments

\begin{tabular}{|l|c|c|c|c|c|}
\hline $\begin{array}{c}\text { Transfusio } \\
\text { n center }\end{array}$ & $\begin{array}{c}\text { Demand } \\
\text { to } \\
\text { deliver : }_{\text {Dem }_{\mathbf{i}}}\end{array}$ & $\begin{array}{c}\text { Availab } \\
\text { le to } \\
\text { pickup : } \\
\text { Pud }_{\mathbf{i}}\end{array}$ & $\begin{array}{c}\text { Earliest } \\
\text { time to } \\
\text { serve: } \mathbf{b}_{\mathbf{i}}\end{array}$ & $\begin{array}{c}\text { Latest } \\
\text { time to } \\
\text { serve: } \mathbf{e}_{\mathbf{i}}\end{array}$ & $\begin{array}{c}\text { Service } \\
\text { time: } \mathbf{s}_{\mathbf{i}}\end{array}$ \\
\hline $\begin{array}{l}\text { Benirtual) } \\
\text { Mellal }\end{array}$ & 0 & 0 & 0 & 700 & 0 \\
\hline $\begin{array}{l}\text { Er- } \\
\text { rachidia }\end{array}$ & 0 & 313 & 0 & 300 & 20 \\
\hline Fez & 385 & 0 & 0 & 500 & 20 \\
\hline Tangier & 0 & 108 & 0 & 300 & 20 \\
\hline Tetouan & 23 & 0 & 0 & 500 & 20 \\
\hline
\end{tabular}


Table 4. transfusion centers Distance matrix

\begin{tabular}{|c|c|c|c|c|c|c|}
\hline Distances & 0 & $\begin{array}{c}\text { Béni } \\
\text { Mellal }\end{array}$ & $\begin{array}{c}\text { Er- } \\
\text { rachidia }\end{array}$ & Fès & Tanger & Tétouan \\
\hline 0 & 0 & 0 & 0 & 0 & 0 & 0 \\
\hline $\begin{array}{c}\text { Béni } \\
\text { Mellal }\end{array}$ & 0 & 0 & 375 & 289 & 538 & 798 \\
\hline Errachidia & 0 & 375 & 0 & 364 & 608 & 604 \\
\hline Fès & 0 & 289 & 364 & 0 & 303 & 281 \\
\hline Tanger & 0 & 538 & 608 & 303 & 0 & 57 \\
\hline Tétouan & 0 & 798 & 604 & 281 & 57 & 0 \\
\hline
\end{tabular}

Table 5. Vehicles parameters in the computational experiments

\begin{tabular}{|c|c|c|c|}
\hline Vehicle & $\begin{array}{c}\text { Capacity } \\
\text { (Blood bag) }\end{array}$ & $\begin{array}{c}\text { Variable cost } \\
\text { (MAD/Km) }\end{array}$ & $\begin{array}{c}\text { Fixed cost } \\
\text { (MAD) }\end{array}$ \\
\hline 1 & 200 & 3 & 600 \\
\hline 2 & 200 & 3 & 600 \\
\hline 3 & 300 & 3 & 675 \\
\hline 4 & 300 & 3 & 675 \\
\hline 5 & 400 & 3 & 725 \\
\hline 6 & 400 & 3 & 725 \\
\hline 7 & 500 & 3 & 750 \\
\hline 8 & 500 & 3 & 750 \\
\hline
\end{tabular}

Table 6. Results of first experiment for Fes Coalition

\begin{tabular}{|c|c|c|c|c|c|c|}
\hline \multirow{7}{*}{$\begin{array}{c}\text { Vehicle } \\
\text { Routing } k=2\end{array}$} & Routing & $\begin{array}{c}\text { Tangier } \\
\text { (Departure) }\end{array}$ & Tetouan & $\begin{array}{l}\text { Tangier } \\
\text { (arrive) }\end{array}$ & & $\begin{array}{l}\text { Vehicle } \\
\text { Capacity }\end{array}$ \\
\hline & $\begin{array}{l}\text { Tik : departure Time } \\
\text { of request }\end{array}$ & $\mathrm{Tdk}=0$ & 55 & Tak $=109.2$ & & \multirow{6}{*}{200} \\
\hline & Time Windows & $0-300$ & $0-500$ & $0-700$ & & \\
\hline & Tasks & $\begin{array}{l}\text { Pickup : } \\
108\end{array}$ & $\begin{array}{l}\text { Deliver : } \\
\quad 23\end{array}$ & Return & & \\
\hline & $\begin{array}{l}\text { Available blood bag : } \\
\text { Gik }\end{array}$ & $\mathrm{Gdk}=0$ & 108 & $\mathrm{Gak}=85$ & & \\
\hline & $\begin{array}{c}\text { Remaining Capacity of } \\
\text { vehicle k: Vik }\end{array}$ & $V d k=200$ & 92 & $\mathrm{Vak}=115$ & & \\
\hline & Dik & \multicolumn{4}{|c|}{57 which is distance between Tetouan and Tangier } & \\
\hline \multirow{7}{*}{$\begin{array}{c}\text { Vehicle } \\
\text { Routing } k=5\end{array}$} & Circuit & $\begin{array}{c}\text { BeniMellal } \\
\text { (Departure) }\end{array}$ & Errachidia & Fez & $\begin{array}{l}\text { BeniMellal } \\
\text { (Arrive) }\end{array}$ & \\
\hline & $\begin{array}{l}\text { Tik : departure Time } \\
\text { of request }\end{array}$ & $\mathrm{Tdk}=0$ & $\begin{array}{c}245 \\
(375 * 0,6+20)\end{array}$ & $\begin{array}{c}484 \\
(245+364 * 0,6+20)\end{array}$ & Tak $=677,4$ & \multirow{6}{*}{400} \\
\hline & Time Windows & $0-300$ & $0-300$ & $0-500$ & $0-700$ & \\
\hline & Tasks & $\begin{array}{l}\text { Pickup : } \\
313\end{array}$ & $\begin{array}{l}\text { Pickup : } \\
76\end{array}$ & $\begin{array}{l}\text { Deliver: } \\
\quad 385\end{array}$ & Return & \\
\hline & $\begin{array}{c}\text { Available blood bag } \\
\text { Gik }\end{array}$ & $\mathrm{Gdk}=0$ & 313 & 389 & Gak $=4$ & \\
\hline & $\begin{array}{c}\text { Remaining Capacity of } \\
\text { vehicle k: Vik }\end{array}$ & $\mathrm{Vdk}=400$ & 87 & 11 & Vak=396 & \\
\hline & Dik & \multicolumn{4}{|c|}{289 which is distance between Fez and Beni-Mellal } & \\
\hline
\end{tabular}


This experiment led to the results shown in Table 6. The average velocity of vehicle is $100 \mathrm{Km} / \mathrm{Hour}$ which is the common velocity of drivers. The experiment validated the robustness of the model. Indeed, the results of this experiment respect all the constraints of the model. The proposed tours are relevant, there is no loop or sub-tours too, all capacities and loads are respected. Transfusion centers are all concerned with the tasks, because it makes it easy to satisfy all the demands. The time windows are met for all transfusion centers and the model gives an optimal objective function of the order of 4751 MAD with a gap of $0 \%$ in 2 seconds. The same job was done for the coalition of Casablanca-EljadidaSafi and the results are shown in the table below.

Table 7. Results of second experiment for Casablanca Coalition

\begin{tabular}{|c|c|c|c|c|c|c|}
\hline \multirow{7}{*}{$\begin{array}{l}\text { Vehicle Routing } \\
\qquad \mathbf{k}=2\end{array}$} & Routing & $\begin{array}{c}\text { Eljadida } \\
\text { (Departure) }\end{array}$ & Safi & Casablanca & $\begin{array}{c}\text { Eljadida } \\
\text { (arrive) }\end{array}$ & $\begin{array}{l}\text { Vehicle } \\
\text { Capacity }\end{array}$ \\
\hline & $\begin{array}{l}\text { Tik : departure Time } \\
\text { of request }\end{array}$ & $\mathrm{Tdk}=0$ & 115 & 289 & Tak $=368.4$ & \multirow{6}{*}{200} \\
\hline & Time Windows & $0-200$ & $0-200$ & $0-300$ & $0-700$ & \\
\hline & Tasks & $\begin{array}{c}\text { Pickup : } \\
76\end{array}$ & $\begin{array}{c}\text { Pickup : } \\
75\end{array}$ & $\begin{array}{c}\text { Deliver : } \\
124 \\
\end{array}$ & Return & \\
\hline & Available blood bag : Gik & $\mathrm{Gdk}=0$ & 76 & 151 & $\mathrm{Gak}=27$ & \\
\hline & $\begin{array}{c}\text { Remaining Capacity of vehicle k: } \\
\text { Vik }\end{array}$ & $\mathrm{Vdk}=200$ & 124 & 49 & Vak=173 & \\
\hline & Dik & \multicolumn{4}{|c|}{$\begin{array}{l}99 \text { which is distance between Casablanca and } \\
\text { Eljadida }\end{array}$} & \\
\hline
\end{tabular}

\subsubsection{Model Extension}

The results of model validation are very interesting, so now things will be viewed with another angle. Instead of fixing coalitions and then search for routing optimization within each coalition, the formulation of HVRPPDTW will be used to define coalitions. That means, in this experiment all the transfusion centers will be introduced then the model will define coalitions based on total transport cost. The first experiment shows difficulties to give a solution with instance of 16 transfusion centers. This fact is explained by the complexity of the resolution due to the increased number of variables and constraints especially as the problem is combinatory. For this reason the model is relaxed via the insulation of three blood centers, tried per default far from a coalition with the centers considered. This relaxation leads to results shown in table 8 . A coalition proposed by HVRPPDTW is not far from the first coalition issue from game theory. Except Marrakech which is included in coalition of Safi-El Jadida-Casablanca, with no particular added-value.

As for the first experimentation the time windows are met for all transfusion centers and the model gives an optimal objective function of the order of 8059 MAD with a gap of $0.41 \%$, but the resolution time is 11498.55 seconds. The latter value confirms the complexity of such problem mentioned above.

Table 8. Results of model extension

\begin{tabular}{|c|c|c|c|c|c|c|c|}
\hline & Routing & $\begin{array}{c}\text { Tangier } \\
\text { (Departure) }\end{array}$ & Tetouane & \multicolumn{2}{|c|}{$\begin{array}{c}\text { Tangier } \\
\text { (arrive) }\end{array}$} & Tehicle \\
Capacity
\end{tabular}




\begin{tabular}{|c|c|c|c|c|c|c|}
\hline & Dik & \multicolumn{4}{|c|}{157 which is distance between Marrakech and Safi } & \\
\hline \multirow{7}{*}{$\begin{array}{c}\text { Vehicle } \\
\text { Routing } \\
\quad k=5\end{array}$} & Circuit & $\begin{array}{r}\text { Errachidia } \\
\text { (Departure) }\end{array}$ & BeniMellal & Fes & $\begin{array}{c}\text { Errachidia } \\
\text { (Arrive) }\end{array}$ & \\
\hline & Tik & $\mathrm{Tdk}=0$ & 245 & 481 & Tak=719.4 & \multirow{5}{*}{400} \\
\hline & TW & $0-360$ & $0-360$ & $0-500$ & $0-720$ & \\
\hline & Tasks & Pickup :76 & Pickup :313 & Deliver:385 & Return & \\
\hline & Gik & $\mathrm{Gdk}=0$ & 76 & 389 & Gak $=4$ & \\
\hline & Vik & $\mathrm{Vdk}=400$ & 324 & 11 & Vak=396 & \\
\hline & Dik & \multicolumn{4}{|c|}{364 which is distance between Fes and Errachidia } & \\
\hline \multirow{7}{*}{$\begin{array}{c}\text { Vehicle } \\
\text { Routing } \\
k=6\end{array}$} & Circuit & $\begin{array}{c}\text { Meknes } \\
\text { (Departure) }\end{array}$ & Rabat & $\begin{array}{l}\text { Meknes } \\
\text { (Arrive) }\end{array}$ & & \\
\hline & Tik & $\mathrm{Tdk}=0$ & 360 & Tak $=462.8$ & & \multirow{5}{*}{400} \\
\hline & TW & $0-360$ & $0-360$ & $0-720$ & & \\
\hline & Tasks & Pickup :190 & Deliver :188 & Return & & \\
\hline & Gik & $\mathrm{Gdk}=0$ & 190 & $\mathrm{Gak}=2$ & & \\
\hline & Vik & $\mathrm{Vdk}=400$ & 210 & Vak $=398$ & & \\
\hline & Dik & \multicolumn{4}{|c|}{138 which is distance between Rabat and Meknes } & \\
\hline
\end{tabular}

Table 9. Evolution of resolution time

\begin{tabular}{|c|c|c|c|c|c|}
\hline $\begin{array}{l}\text { Number } \\
\text { of cities }\end{array}$ & $\begin{array}{l}\text { Number of } \\
\text { Coallition }\end{array}$ & Coallition & $\begin{array}{l}\text { Resolution Time } \\
\text { (Seconds) }\end{array}$ & GAP & Actions \\
\hline 5 & 2 & $\begin{array}{c}\text { Meknès-Rabat } \\
\text { Errachidia-Bénimellal-Fès }\end{array}$ & 8.95 & $10 \%$ & \\
\hline 6 & 3 & $\begin{array}{c}\text { Meknes-Rabat } \\
\text { Eljadida -BeniMellal-Fes } \\
\text { Errachidia } \\
\end{array}$ & 13.12 & $17 \%$ & Eljadida added \\
\hline 7 & 4 & $\begin{array}{c}\text { Meknes-Rabat } \\
\text { Eljadida -BeniMellal-Fes } \\
\text { Safi } \\
\text { Errachidia }\end{array}$ & 138.65 & $3 \%$ & Safi Added \\
\hline 8 & 3 & $\begin{array}{c}\text { Meknes-Rabat } \\
\text { Errachidia-BeniMellal-Fes } \\
\text { Eljadida-Safi-Casablanca }\end{array}$ & 456.9 & $6 \%$ & Casablanca Added \\
\hline 11 & 5 & $\begin{array}{c}\text { Agadir } \\
\text { Ouarzazate } \\
\text { Meknes-Rabat } \\
\text { Safi-Eljadida-Casablanca-Marrakech } \\
\text { Errachidia-BéniMellal-Fes }\end{array}$ & 10634.18 & $0.35 \%$ & $\begin{array}{l}\text { Agadir-Ouarzazate and } \\
\text { Marrakech Added }\end{array}$ \\
\hline 13 & 6 & $\begin{array}{c}\text { Agadir } \\
\text { Ouarzazate } \\
\text { Meknes-Rabat } \\
\text { Safi-Eljadida-Casablanca-Marrakech } \\
\text { Errachidia-BéniMellal-Fes } \\
\text { Tanger-Tetouane }\end{array}$ & 11498.55 & $0.41 \%$ & $\begin{array}{c}\text { Tangier and Tetouane } \\
\text { added }\end{array}$ \\
\hline
\end{tabular}


Resolution time increase considerably, when the number of cities is incremented as shown in Table 9. With the instance of 16 cities, the program diverges and returns no result.

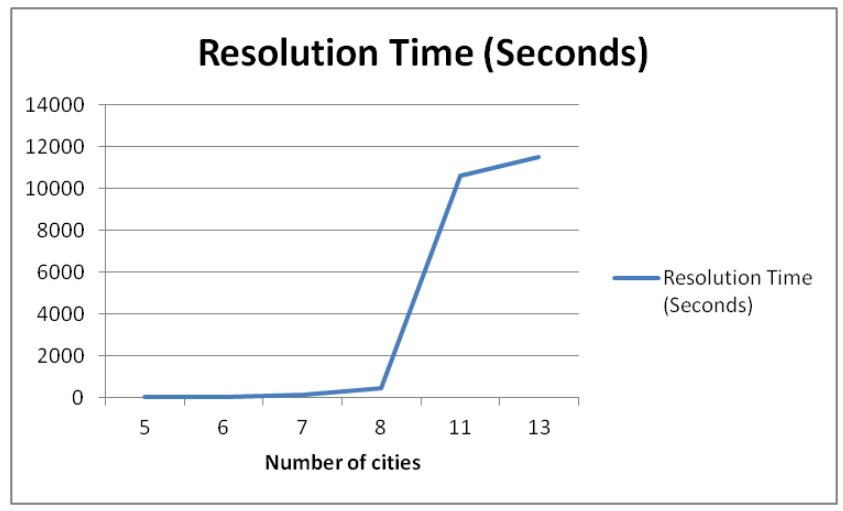

Fig 2 : Evolution of resolution time in function of cities' number

\section{CONCLUSION}

Motivated by the context of collaborative supply chain of blood, this study propose a new way to design a set of coalition in order to satisfy customer demand and optimize transport cost in Less than Truck-Load transportation mode (LTL). First, a linear integer program is formulated to generate the optimal costs of each of the 33 coalitions approved by the Director of NBTHC. And then these costs are used as data of two other MILP to determine which coalitions form to meet the demands of patients and which combination will be core and strongly stable.

A third MILP is also introduced to optimize vehicle routing within each coalition. This model minimizes the total cost of transport generated by fixed and variable costs associated to vehicles. This model, rated as HVRPPDTW, take into account the heterogeneity of the fleet and the self choice of tour starting point. Model validation was performed on a solver, and showed the model's relevance. Then the possibility of defining coalitions directly from this MILP was evaluated.

This approach has achieved the desired objective, which is the satisfaction of demand while optimizing the cost of transportation. A sizeable cost value of unmet requests was assigned to make other transportation costs and unused bags negligible. This study was able to optimize the procurement process and the end result was a set of self-sustaining coalitions.

The experiment results showed that the larger institutions reinforce the complexity of the model, where the processing time becomes long. In addition, from a number of transfusion centers (15 in this case), the computer and the software available cannot give effective results. To better understand this issue of problem size, in a future study treatment via meta-heuristic; known for their efficiency in solving time even for large instances; will be interesting.

Also, for better contribution in the context of this scientific research, an interface will be created between the model and a map, taking into account the dynamics of routes information.

\section{REFERENCES}

[1] R. Aumann, "Acceptable points in general cooperative nperson Games," Contrib. to Theory Games, vol. 40, pp. 287-324, 1959.

[2] M. Shubik, "Incentives, decentralized control, the assignment of joint costs and internal pricing," Manage. Sci., 1962

[3] M. Shubik, "Game theory and operations research: some musings 50 years later," Oper. Res., 2002.

[4] A. V. Smirnov, L. B. Sheremetov, N. Chilov, and J. R. Cortes, "Soft-computing technologies for configuration of cooperative supply chain," Appl. Soft Comput. J., vol. 4, no. 1, pp. 87-107, 2004.

[5] M. Jin and S. D. Wu, "Supplier coalitions in on-line reverse auctions: Validity requirements and profit distribution scheme," Int. J. Prod. Econ., vol. 100, no. 2, pp. 183-194, 2006.

[6] S. L. Charles and D. R. Hansen, "An evaluation of activity-based costing and functional-based costing: A game-theoretic approach," Int. J. Prod. Econ., vol. 113, no. 1, pp. 282-296, 2008.

[7] J. Drechsel and A. Kimms, "Computing core allocations in cooperative games with an application to cooperative procurement," Int. J. Prod. Econ., vol. 128, no. 1, pp. 310-321, 2010.

[8] M. Nagarajan and G. Sošic, "Coalition stability in assembly models," Oper. Res., 2009.

[9] M. Nagarajan and Y. Bassok, "A bargaining framework in supply chains: The assembly problem," Manage. Sci., 2008.

[10] G. Reinhardt and M. Dada, "Allocating the gains from resource pooling with the Shapley value," J. Oper. Res., 2005.

[11] G. Sošic, "Transshipment of inventories among retailers: Myopic vs. farsighted stability,” Manage. Sci., 2006.

[12] X. Chen, "Inventory Centralization Games with PriceDependent Demand and Quantity Discount," Oper. Res., vol. 57, no. 6, pp. 1394-1406, Dec. 2009.

[13] U. Özen, J. Fransoo, and H. Norde, "Cooperation between multiple newsvendors with warehouses," Manuf. Serv., 2008.

[14] M. Frisk, M. Göthe-Lundgren, K. Jörnsten, and M. Rönnqvist, "Cost allocation in collaborative forest transportation," Eur. J. Oper. Res., vol. 205, no. 2, pp. 448-458, 2010.

[15] S. Lozano, P. Moreno, B. Adenso-Díaz, and E. Algaba, "Cooperative game theory approach to allocating benefits of horizontal cooperation," Eur. J. Oper. Res., vol. 229, no. 2, pp. 444-452, 2013.

[16] M. Guajardo and M. R??nnqvist, "Operations research models for coalition structure in collaborative logistics," Eur. J. Oper. Res., vol. 240, no. 1, pp. 147-159, 2015.

[17] S. D'Amours and M. Rönnqvist, "Issues in Collaborative Logistics," Springer Berlin Heidelberg, 2010, pp. 395409.

[18] Bennis, "Apport de la modélisation , optimisation et simulation aux systèmes hospitaliers: Application au laboratoire $\mathrm{d}$ ' analyse de biologie médicale et au processus de transfusion sanguine," 2014.

[19] M. G. Fiestras-Janeiro, I. García-Jurado, A. Meca, and M. A. Mosquera, "Cooperative game theory and inventory management," Eur. J. Oper. Res., vol. 210, no. 
3, pp. 459-466, 2011.

[20] X. Hu, R. Caldentey, and G. Vulcano, "Revenue sharing in airline alliances," Manage. Sci., 2013.

[21] D. Gillies, "Solutions to general non-zero-sum games," Contrib. to Theory Games, 1959.

[22] L. Xue, Z. Luo, and A. Lim, "Exact approaches for the pickup and delivery problem with loading cost," Omega, vol. 59, pp. 131-145, 2016.

[23] M. M. S. Abdulkader, Y. Gajpal, and T. Y. Elmekkawy, "Hybridized ant colony algorithm for the Multi Compartment Vehicle Routing Problem," Appl. Soft Comput. J., vol. 37, pp. 196-203, 2015.

[24] G. B. Dantzing and J. H. Ramser, "The Truck Dispatching Problem," Manage. Sci., vol. 6, no. 1, pp. 80-91, 1959.

[25] B. Kallehauge, J. Larsen, and O. B. G. Madsen, "Lagrangian duality applied to the vehicle routing problem with time windows," Comput. Oper. Res., vol. 33 , no. 5, pp. 1464-1487, 2006.

[26] M. M. Solomon, "Algorithms for the Vehicle Routing and Scheduling Problems with Time Window Constraints," Oper. Res., vol. 35, no. 2, pp. 254-265, 1987.

[27] D. Ta??, N. Dellaert, T. Van Woensel, and T. De Kok, "Vehicle routing problem with stochastic travel times including soft time windows and service costs," Comput. Oper. Res., vol. 40, no. 1, pp. 214-224, 2013.

[28] M. A. Figliozzi, "An iterative route construction and improvement algorithm for the vehicle routing problem with soft time windows," Transp. Res. Part C Emerg. Technol., vol. 18, no. 5, pp. 668-679, 2010.

[29] A. Agra, M. Christiansen, R. Figueiredo, L. M. Hvattum, M. Poss, and C. Requejo, "The robust vehicle routing problem with time windows," Comput. Oper. Res., vol. 40, no. 3, pp. 856-866, 2013.

[30] T. Vidal, T. G. Crainic, M. Gendreau, and C. Prins, "A hybrid genetic algorithm with adaptive diversity management for a large class of vehicle routing problems with time-windows," Comput. Oper. Res., vol. 40, no. 1, pp. 475-489, 2013.

[31] E. D. Taillard, "A heuristic column generation method for the heterogeneous fleet VRP," RAIRO - Oper. Res., vol. 33, no. 1, pp. 1-14, 1999.

[32] Y. Dumas, J. Desrosiers, and F. Soumis, "The pickup and delivery problem with time windows," Eur. J. Oper. Res., vol. 54, no. 1, pp. 7-22, Sep. 1991.

[33] S. Ropke and J.-F. Cordeau, "Branch and Cut and Price for the Pickup and Delivery Problem with Time Windows," Transp. Sci., vol. 43, no. 3, pp. 267-286, 2009.

[34] R. Baldacci, E. Bartolini, and A. Mingozzi, "An Exact Algorithm for the Pickup and Delivery Problem with Time Windows," Oper. Res., vol. 59, no. 2, pp. 414-426, Apr. 2011.

[35] M. Cherkesly, G. Desaulniers, S. Irnich, and G. Laporte, "Branch-price-and-cut algorithms for the pickup and delivery problem with time windows and multiple stacks," Eur. J. Oper. Res., vol. 250, no. 3, pp. 782-793, 2016. 